\title{
Synthesis and investigation of antimicrobial properties of pyrrolidine appended calix[4]arene
}

\author{
Saba Muneer ${ }^{1}$, Shahabuddin Memon ${ }^{1 *}$, Qadeer Khan Pahnwar ${ }^{2}$, Asif Ali Bhatti ${ }^{1}$ and Tahira Sarwar Khokhar ${ }^{1}$
}

\begin{abstract}
Background: Calixarenes are widely used macromolecules in supramolecular chemistry synthesized by simple phenol formaldehyde condensation reaction in the presence of base. This article describes the synthesis, antibacterial, and antifungal properties of calix[4]arene appended with pyrrolidine at the upper rim (CAP3).

Methods: Antimicrobial activity of CAP3 was determined by Kirby-Bauer well agar diffusion method in Mueller-Hinton agar (MHA) medium of growth against Escherichia coli (ATCC 8739), Staphylococcus aureus (ATCC 10231) and Streptococcus viridans (ATCC 12392), Candida albicans (ATCC 32333), Aspergillus niger (ATCC 16404), and Aspergillus flavus (ATCC 90906). Structure-activity relationship was also used to evaluate the active site of CAP3.

Results: Bacterial strains have shown minimum inhibitory concentration (MIC) values in 1.17-2.34 mg/mL range; whereas, the fungal strains have shown MIC values at the range of $0.58-2.34 \mathrm{mg} / \mathrm{mL}$. It is observed that CAP3 has excellent antifungal action for A. niger as well as antibacterial action for S. viridans having MIC values of 0.58 and $1.17 \mathrm{mg} / \mathrm{mL}$, respectively. The SAR (structure-activity relationship) study of compound reveals that there is a significant antimicrobial activity shown by CAP3 probably due to the pyrrolidine substituents at phenyl rings of calix[4]arene.
\end{abstract}

Conclusions: The results indicate that CAP3 is an effective material against the microbial strains.

Keywords: Pyrrolidine, Calix[4]arene, Structure-activity relationship, MIC, Antimicrobial activity

\section{Background}

Because of diverse bioactive and potential pharmaceutical characteristics, pyrrolidine and related heterocyclic compounds have possessed specific position among diverse organic classes (Pinto and Abdala 2000). From the last few decades, these molecules have got considerable attention in pharmaceutical industry due to the extensive clinical requests (Mohammat et al. 2011; Feng et al. 2012). It is because of the outstanding antiviral and antibiotic properties of these molecules caused by heterocyclic core, such as pyrrolidine-2,4-dione (natural tetramic acids) (Gallardo et al. 2004; Gitterman et al. 1964; Chen et al. 2008; Gitterman 1965; la Croix et al. 1975; Janardhanan and Husain 1984; Suzuki et al. 1967; Mourer et al.

\footnotetext{
* Correspondence: shahabuddinmemon@yahoo.com

${ }^{1}$ National Centre of Excellence in Analytical Chemsitry, University of Sindh, Jamshoro 76080, Pakistan

Full list of author information is available at the end of the article
}

2009). Arun et al. has prepared and estimated the antimicrobial activity of dispirooxindole-pyrrolidine derivatives via 1,3-dipolar cycloaddition of an azomethine ylide obtained from sarcosine and isatin. Dandia et al. prepared spiro[acenaphthylene-1,2'-pyrrolidine] in the course of 1,3-dipolar cycloaddition reaction of azomethine ylide generated from sarcosin and di/tri ketone. The cycloadducts ketocarbazalo spiro N-methyl pyrrolidines have demonstrated highly remarkable antimicrobial activity even in very low concentrations (Dandia et al. 2013). However, importance in drug delivery and potentially enhanced neuroprotection and anticancer properties often found in novel compounds. In the last few decades, calixarene molecules are found to have multiple uses in basic as well as applied sciences. They are also a class of important macrocyclic molecules like cyclodextrins, crown ethers, and porphyrins, which act as host molecules. Structure of 

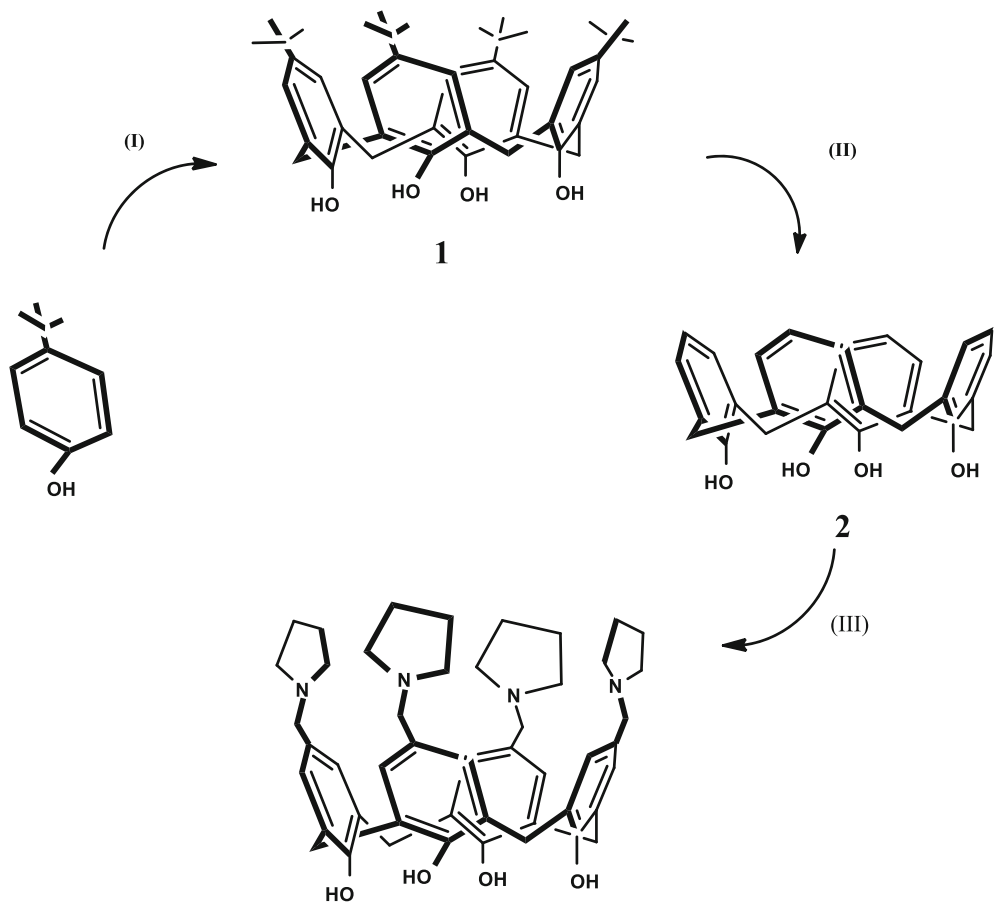

3

Scheme 1 Synthesis of CAP3 (I) HCHO/NaOH, (II) AlCl$/$ /Phenol and (III) $\mathrm{CH}_{3} \mathrm{COOH} / \mathrm{THF}$, Pyrrolidine/HCHO

calixarenes possesses the lower and upper rims with central annulus part joined via methylene groups, while hydroxyl functionality at meta-position (Memon and Bhatti 2015; Fátima and Fernandes 2009). Because of easy functionalization at the upper and lower rims, calixarenes are widely used in various fields like molecular recognition, nanotechnology, catalysis, sensing, drug delivery, and to mimic the biological processes (Nimsea and Kim 2013). The molecular recognition property makes them a versatile tool for complexation of organic and biomolecules. In this regard, the pioneer work is done by Cornforth et al. against tuberculosis (TB), which will prove to explore the calixarenes' for examining their biological properties. Furthermore, several pharmacological properties including antibacterial, antifungal, antiviral, and anticancer activities (Colston et al. 2004) of calixarenes have also been reported. Thus, herein, we report the synthesis and investigation of calix[4] arene (CAP3) containing pyrrolidine moiety and divulge the remarkable screening results against its antibacterial and antifungal activities.

\section{Methods}

For synthesis, all reagents were of analytical grade and used without further purification. Mueller-Hinton agar was purchase from Sigma-Aldrich; antimicrobial growth was performed locally prepared at laminar flow cabinet. Preparation of medium was done on vertical autoclave (i.e., Robus
Technologies). Antimicrobial growth was carried out on Thermo Scientific incubator. Gallenkamp melting point apparatus was used for the melting point determination and was uncorrected. Elemental analysis was carried out using a CHNS instrument model Flash EA 1112 elemental analyzer. FT-IR spectra were obtained by applying $\mathrm{KBr}$ pellet method in the spectral range $400-4000 \mathrm{~cm}^{-1}$ on a Thermo Nicollet 5700 FT-IR spectrometer. TLC was carried out on pre-coated silica gel plates (SiO2, Merck PF254).

\section{Synthesis of compound}

5,11,17,23-tetra-tert-butyl-25,26,27,28-tetrahydroxycalix[4] arene (1), 25,26,27,28-tetrahydroxycalix[4] arene (2) as well as 5,11,17,23-tetrakis(N-pyrrolidinomethyl)-25,26,27, 28-tetrahydroxycalix[4]arene) (3) have been prepared (Scheme 1) following the literature methods (Gutsche and Nam 1988). Various types of instrumental techniques used to validate the synthesis of CAP3 such as melting

Table 1 Distribution of culture strains and medium

\begin{tabular}{llll}
\hline & G +ve bacteria & G -ve bacteria & Fungi \\
\hline Microorganisms & S. aureus & E. coli & A. niger \\
& S. viridans & A. flavus \\
& & C. albicans \\
Medium & Mueller-Hinton agar & \\
\hline
\end{tabular}


Table 2 Zones of inhibition for antimicrobial activities of CAP3

\begin{tabular}{|c|c|c|c|c|c|c|c|c|c|c|}
\hline \multirow[t]{2}{*}{ Microorganism strain } & \multicolumn{9}{|c|}{ Concentration $(\mathrm{mg} / \mathrm{mL})$} & \multirow[t]{2}{*}{ MIC value $(\mathrm{mg} / \mathrm{mL}$} \\
\hline & & 0.58 & 1.17 & 2.3 & 4.7 & 9.4 & 18.7 & 37.5 & 75 & \\
\hline Bacterial strain & \multicolumn{10}{|c|}{ Zones of inhibition (mm) } \\
\hline \multirow[t]{2}{*}{ G +ve bacteria } & S. aureus & - & - & 17 & 19 & 21 & 25 & 27 & 28 & 2.3 \\
\hline & S. viridans & - & 16 & 17 & 19 & 25 & 25 & 28 & 31 & 1.17 \\
\hline G -ve bacteria & E. coli & - & - & 13 & 15 & 19 & 20 & 23 & 24 & 2.3 \\
\hline \multirow[t]{3}{*}{ Fungi } & A. niger & 16 & 19 & 20 & 22 & 27 & 29 & 31 & 32 & 0.58 \\
\hline & A. flavus & - & 15 & 16 & 18 & 21 & 21 & 23 & 26 & 1.17 \\
\hline & C.albicans & - & - & 13 & 14 & 17 & 19 & 19 & 20 & 2.3 \\
\hline Control $(\mathrm{DMSO})^{\dagger}$ & & $-v e$ & -ve & $-v e$ & $-v e$ & ve & -ve & -ve & -ve & - \\
\hline
\end{tabular}

${ }^{\dagger}$ DMSO solvent was used as -ve control

point, TLC, and elemental analysis as well as FT-IR techniques.

\section{5,11,17,23-tetrakis (N-pyrrolidinomethyl)-25,26,27,28- tetrahydroxycalix[4]arene)}

$2.8 \mathrm{mmol}$ of compound (2) was dissolved in $45 \mathrm{~mL}$ of THF with of $37 \%$ formaldehyde $(12 \mathrm{mmol})$ added drop wise to reaction mixture at room temperature. By the addition of pyrrolidine $(12 \mathrm{mmol})$, the reaction mixture start to become yellowish wax type. The solution was stirred for $24 \mathrm{~h}$ and filtered, washed with water and crystallized in methanol to furnished (3).

\section{Antimicrobial studies}

The biological activities of pyrrolidine appended calix[4]arene CAP3 have been explored, which exhibited excellent antibacterial and antifungal activities. These activities were evaluated using well diffusion method. The dimethylsulphoxide (DMSO) has been used as -ve control with standard solution of $(150 \mathrm{mg} / \mathrm{mL})$ has been prepared (Volonterio and Zanda 2008). The antifungal property has been carried out against Aspergillus niger and Candida albicans as well as Aspergillus flavus. Likewise, antibacterial property has been studied against Gram +ve (Staphylococcus aureus and Streptococcus viridans) as well as Gram -ve (Escherichia coli). Study has revealed that CAP3 is significantly effective against both the strains. Inhibition zones have been measured in millimeter $(\mathrm{mm})$ for all microorganisms. MIC (minimum inhibitory concentration) data has also been evaluated for the same species (Table 1) provide classification of bacterial, fungal species, and medium.

\section{Microbial assay}

Various methods were employed for the determination of the antimicrobial activity. Antimicrobial activity of CAP3 was tested by using Kirby-Bauer well diffusion method (Perret and Coleman 2011). Different concentrations were used for compound CAP3 ranging from 75.0, 37.5, 18.7, 9.37, 4.68, 2.34, 1.17, and $0.58 \mathrm{mg} / \mathrm{mL}$ in dimethylsulphoxide (DMSO) (Zgoda and Porte 2001). A well was developed in the sterile Petri dish with medium

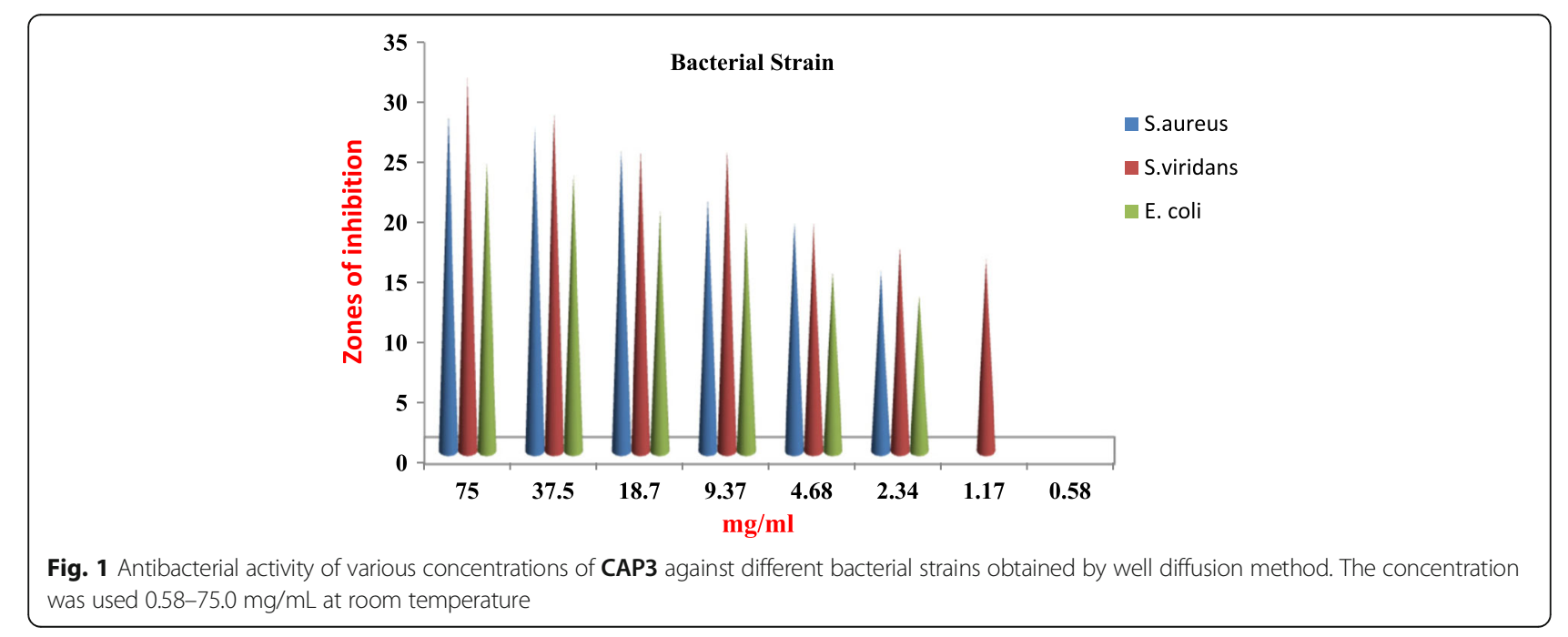




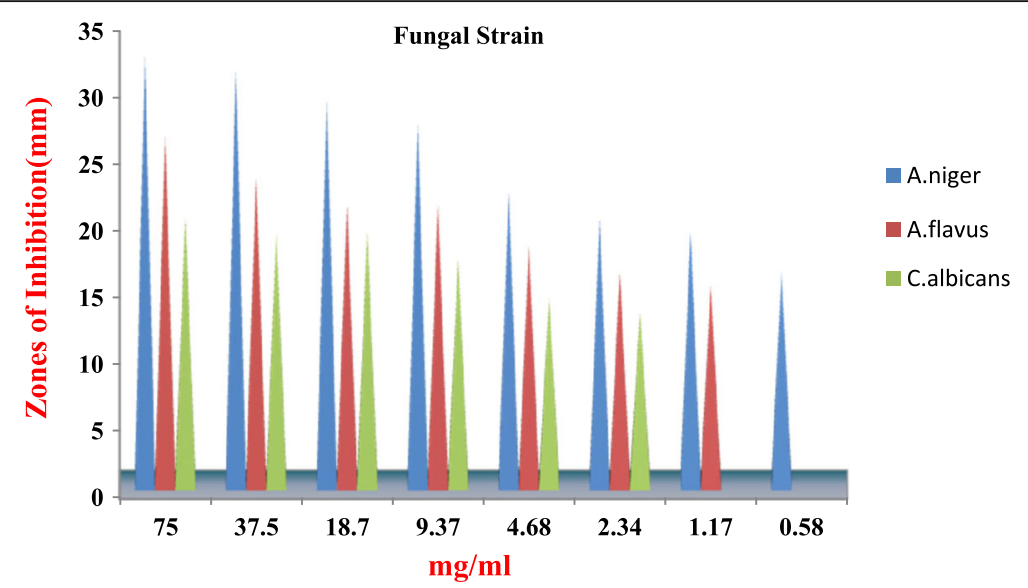

Fig. 2 Antifungal activity of various concentrations of CAP3 obtained by way of well diffusion method. At room temperature and concentration was used $0.58-75.0 \mathrm{mg} / \mathrm{mL}$

plates were prepared with the help of cork borer $(6 \mathrm{~mm}$ in diameter) and $(50 \mu \mathrm{L})$ solution of each concentration was poured into the wells. Under sterilized condition, wells were filled with diluted solution; micropipette was used for filling purpose. This work was done at room temperature and stored them for further use. Sterilized Petri dishes were incubated for $48 \mathrm{~h}$ at $37{ }^{\circ} \mathrm{C}$. At the same time, DMSO as -ve control was employed, and the solution of CAP3 was also prepared in the same solvent. While the relative antifungal and antibacterial activities in millimeter were measured for evaluation. The results were studied in triplicate. MIC data have also been appraised (Dumazet et al. 1997; Mistry and Desai 2014).

\section{Results and discussion}

Calixarenes have been proved to be a good platform for number of valuable bioactive compounds/molecules (Fátima and Fernandes 2009). The antimicrobial activity of CAP3 compound was studied using well diffusion method against Gram +ve and Gram -ve bacteria as well as fungi. Thus, it is observed that the antibacterial as well as antifungal action of CAP3 derivative is significant as presented in (Table 2).

It shows that CAP3 exhibits good antibacterial action against Gram +ve bacteria comparative to Gram -ve. It also shows better antifungal activity against $A$. niger than all other selected fungal strains due to morphological change in their structures.

\section{Antibacterial activity}

Number of polymers like calix[4]arene have shown antibacterial action, the first study emerged in 1955; in that study, macrocyclon has efficiently worked against tuberculosis, vancomycin, and some other types of mycobacteriosis models (Casnati et. al. 1996; Cornforth et al. 1955).
The antibacterial action of newly prepared CAP3 derivative has been comprehensively explored and calculated against various species of Gram +ve bacteria such as $S$. viridans and $S$. aureus and bacteria like E. coli (Gram -ve) (Muneer et al. 2016; Rao and Chakraborty 2014). CAP3 shows appreciably good antibacterial action for S. viridans (Gram +ve bacteria), while it shows variations against other antibacterial strains (Fig. 1) (Saba et al. 2015).

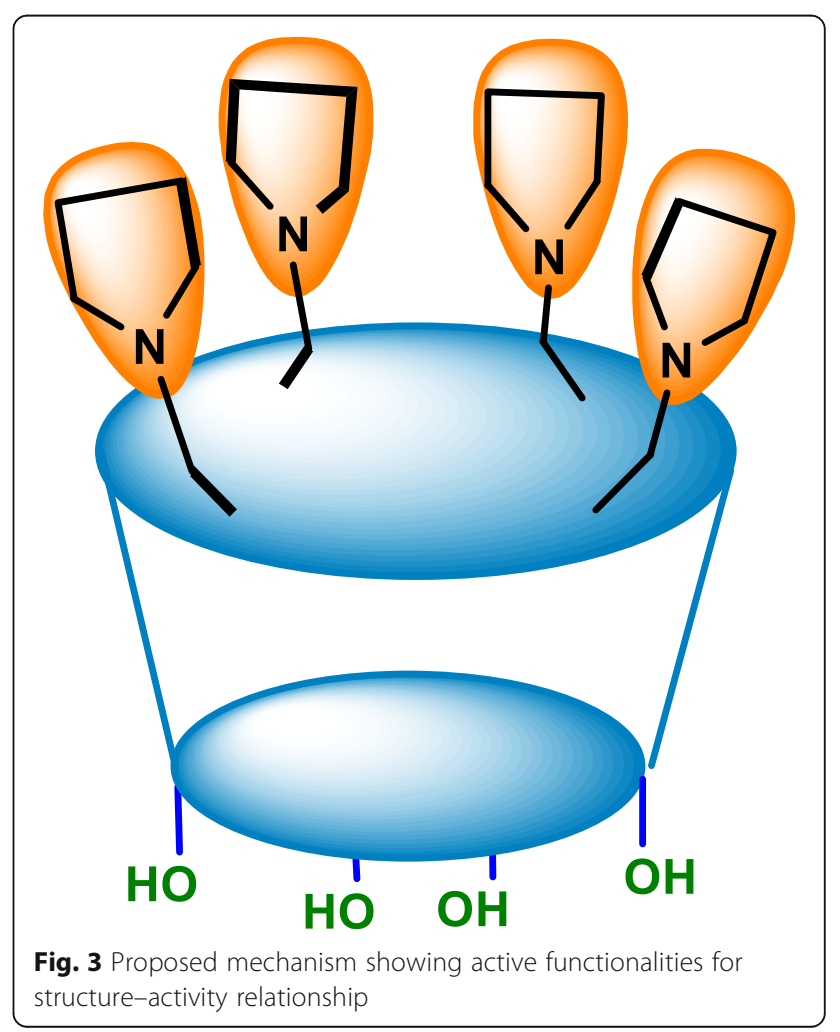




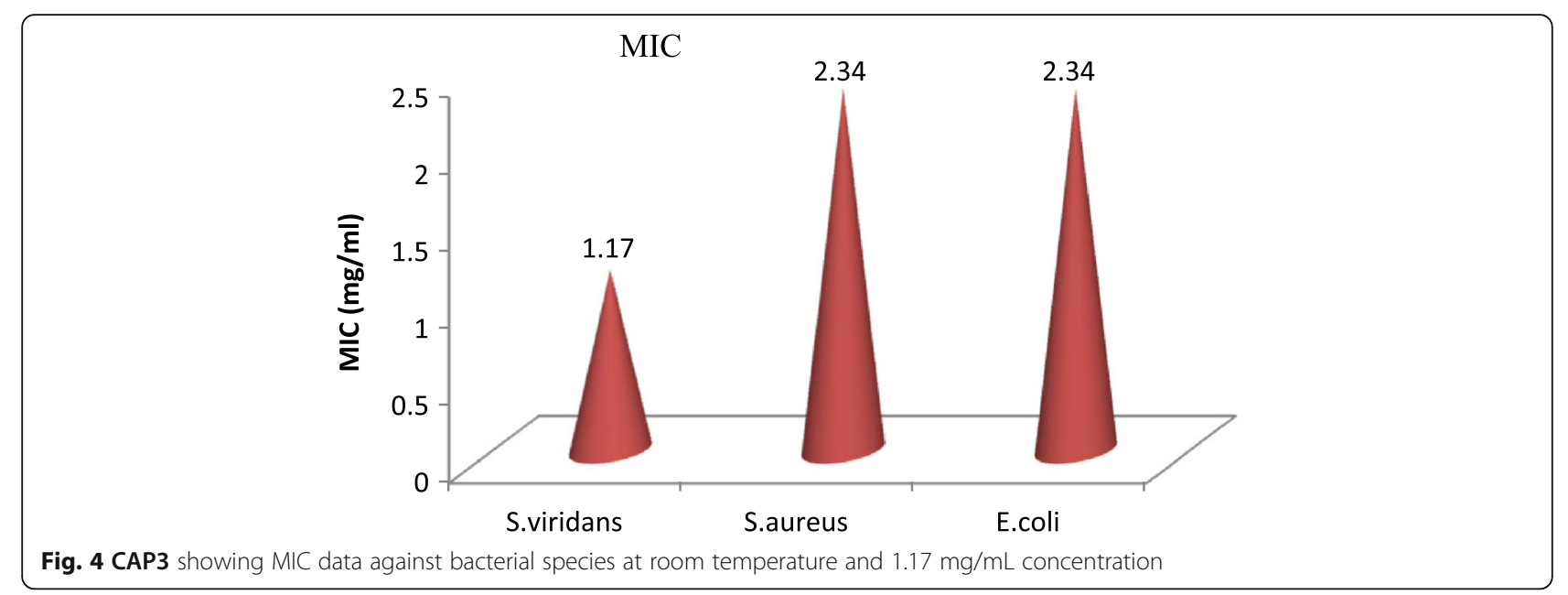

\section{Antifungal activity}

CAP3 has also been examined for antifungal action against $C$. albicans, $A$. flavus, and $A$. niger. The results show that it effectively inhibit fungal species. Among them, A.niger has displayed the biggest zone of inhibition than remaining fungal species due to morphologically changed structures; thus, CAP3 is more active against $A$. niger for antifungal strain (Fig.2).

\section{Structure-activity relationship hypothesis}

Structure-activity relationship (SAR) evaluation clarifies that electron-donating/electron-withdrawing groups in compounds are found to have more antimicrobial properties relative to their precursors. The pyrrolidine ring type compounds due to structural variation show more bioactivity and attract attention of many research groups. Tsou and coworkers have also reported some natural molecules, which include 2-aryl pyrrolidine type skeleton (Han et al. 2012). However, the derivative has increased its antimicrobial action because of electron releasing moieties causing net increase than precursor as shown in graphical structure (Fig.3).

\section{Minimum inhibitory concentration}

The necessary concentration required for inhibiting completely the growth of bacterial and fungal strain is called minimum inhibitory concentration (MIC) (Wang et al. 2015; Mojab et al. 2008). However, quantitatively valuable MIC data have been assessed for CAP3 using different concentration extending from 75.0, 37.5, 18.7, 9.37, 4.68, 2.34, 1.17 up to $0.58 \mathrm{mg} / \mathrm{mL}$ for testing the fungal and bacterial strains. The data have been provided in (Table 2) as well as illustrated in (Fig. 4). MIC data have described a significant antibacterial activity of compound CAP3 for S.viridans at $1.17 \mathrm{mg} / \mathrm{mL}$ as given in (Fig. 4). S. aureus is found to have lower antibacterial action at $2.34 \mathrm{mg} / \mathrm{mL}$

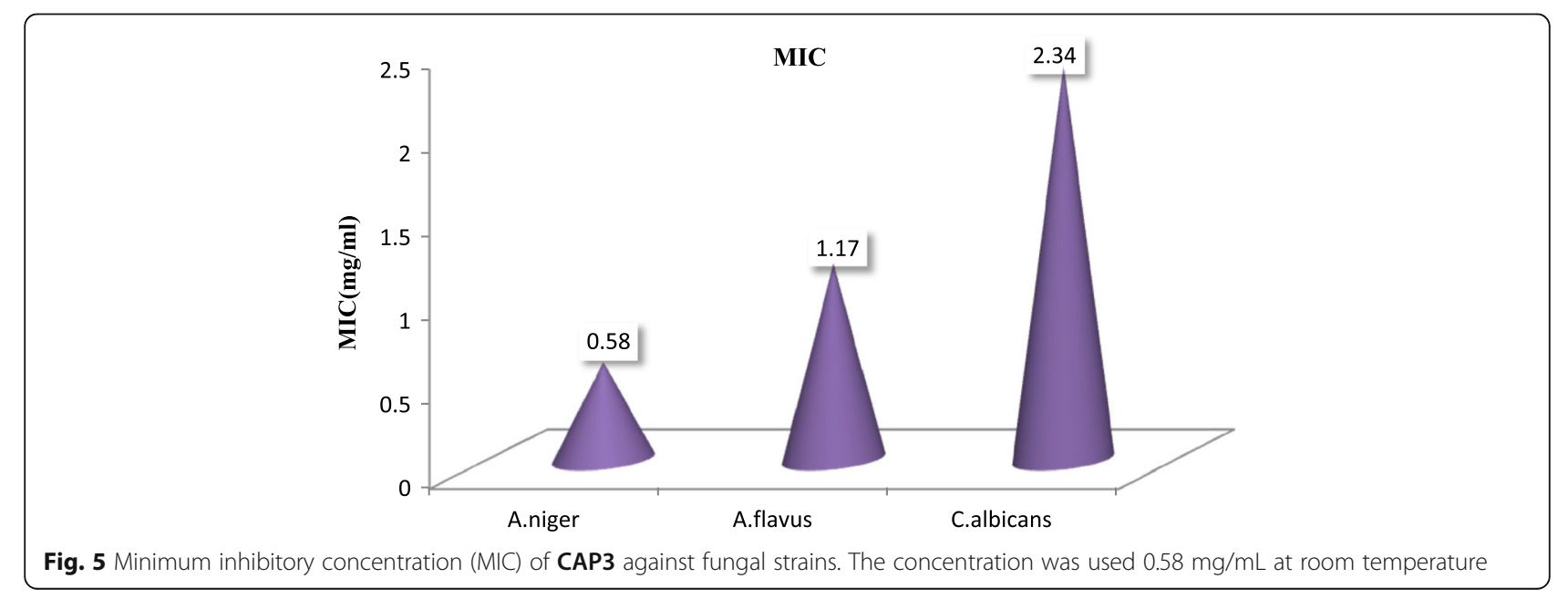


MIC value. In addition, E. coli has also lower activity showing MIC value of $2.34 \mathrm{mg} / \mathrm{mL}$.

MIC value of compound CAP3 for antifungal activity has been observed in $0.58-2.3 \mathrm{mg} / \mathrm{mL}$ range. It illustrates good antifungal activity against $A$. niger at the concentration of $0.58 \mathrm{mg} / \mathrm{mL}$, while the MIC data of CAP3 against A. flavus is $1.17 \mathrm{mg} / \mathrm{mL}$ which seem to be the moderate antifungal activity; whereas it has shown very low activity at $2.34 \mathrm{mg} / \mathrm{mL}$ concentration against C. albicans (Fig. 5).

\section{Conclusions}

In the present study, pyrrolidine appended calix[4]arene (CAP3) was synthesized and explored for its antimicrobial activity using Kirby-Bauer well agar diffusion method. The study revealed that CAP3 show good antimicrobial activity against selected bacterial and fungal strains. The MIC values calculated are in the range 1.17-2.34 and 0.58$2.34 \mathrm{mg} / \mathrm{mL}$ for bacterial and fungal strains, respectively. The convenient synthetic scheme and low toxicity as well as cost effectiveness of the starting materials make CAP3 a promising candidate for the pharmaceutical formulations against the tested microorganisms. Consequently, the study shows a good impact for controlling the infections created by different microorganism in future.

\section{Authors' contribution}

All authors read and approved the final manuscript.

\section{Competing interest}

The authors declare that they have no competing interests.

\section{Author details}

${ }^{1}$ National Centre of Excellence in Analytical Chemsitry, University of Sindh, Jamshoro 76080 , Pakistan. ${ }^{2}$ Dr. M. A. Kazi Institute of Chemistry, University of Sindh, Jamshoro 76080, Pakistan.

Received: 16 August 2016 Accepted: 24 January 2017

Published online: 09 February 2017

\section{References}

Casnati AC, Fabbi M, Pelizzi N. Synthesis, antimicrobial activity and binding properties of calix[4]arene based vancomycin mimics. Bioorg Med Chem Lett. 1996;6:2699-704.

Chen SG, Yin CY, Dai XB. Action of tenuazonic acid, a natural phytotoxin, on photosystem II of spinach. Environ Exp Bot. 2008;6:279-84.

Colston MJ, Hailes HC, Stavropoulos E. Antimycobacterial calixarenes enhance innate defense mechanisms in murine macrophages and induce control of mycobacterium tuberculosis infection in mice. Infect Immun. 2004;1 1:6318-23.

Cornforth JW, Hart PD, Nicholls GA. Antituberculous effects of certain surfaceactive polyoxyethylene ethers. Brit J Pharmacol Chemother. 1955;10:73-8.

Dandia A, Kumari S, Soni P. Synthesis and biological evaluation of spiro[acenaphthylene-1,2'-pyrrolidine] derivatives. Eur Chem Bull. 2013;2:1004-8.

Dumazet I, Regnouf de Vains JB, Lamartine R. Synthesis and characterization of p-tert-butyl-calix[9, 10, 11 and 12]arenes. Synth Commun. 1997;27:2547-55.

Fátima A, Fernandes. Calixarenes as new platforms for drug design. Curr Drug Discov Technol. 2009;6:151-70

Feng HB, Shi QM, Wang XF. Synthesis and bioactivity of novel 3-(1hydroxyethylidene)-5-substituted-pyrrolidine-2, 4-dione derivatives. J Chin Chem Letters. 2012;23:1023-26.

Gallardo GL, Peña NI, Chacana P. L-Tenuazonic acid, a new inhibitor of Paenibacillus larvae. World J Microb Biotechnol. 2004;20:609-14.

Gitterman CO. Antitumor, cytotoxic, and antibacterial activities of tenuazonic acid and congeneric tetramic acids. J Med Chem. 1965;8:483-86.
Gitterman CO, Dulaney EL, Kaczka EA. The human tumor-egg host system III. Tumor-inhibitory properties of tenuazonic acid. J Cancer Res. 1964;24:440-43.

Gutsche CD, Nam KC. Synthesis, properties, and metal complexation of amino calixarenes. J Am Chem Soc. 1988;110:6153-62.

Han BF, Shi QM, Wang XF. Synthesis and bioactivity of some 2-oxo-5-aryl-3hydrazone and 2-oxo-5-aryl-4-hydrazone pyrrolidine derivatives. Chinese Chem Lett. 2012;23:1023-26.

Janardhanan KK, Husain A. Phytotoxic activity of tenuazonic acid isolated from Alternaria alternata (Fr.) Keissler causing leaf blight of Datura innoxia Mill. and its effect on host metabolism. Phytopathology. 1984;111:1305-11.

la Croix EAS, Mhasalkar SE, Mamalis P. Insecticidal activity of some tenuazonic acid analogues. Pestic Sci. 1975;6:491-96.

Memon S, Bhatti AA. Cu ${ }^{2+}$ selective chromogenic behavior of calix[4]arene derivative. Polycycl Aromat Comp. 2015:36(4):395-409.

Mistry PP, Desai VA. Evaluating one-pot synthesis of 3,5-substituted hydantoins and their biological studies. Der Chemica Sinica. 2014;3:1198-3.

Mohammat MF, Najim N, Mansor NS. Synthesis and bioactivity of some 2-oxo-5aryl-3-hydrazone and 2-oxo-5-aryl-4-hydrazone pyrrolidine derivatives. J. ARKAT-USA Inc. (ix); 2011. p. 429-38.

Mojab F, Poursaeed M, Mehrgan H. Antibacterial activity of Thymus daenensis methanolic extract. Pak J Pharm Sci. 2008;21:210-13.

Mourer M, Dibama HM, Fontanay S. p-Guanidinoethyl calixarene and parent phenol derivatives exhibiting antibacterial activities. Synthesis and biological evaluation. Bioorg Med Chem. 2009;17:5496-09.

Muneer S, Memon S, Panhwar QK, Khushik F, Khokhar TS, Noor AA. Synthesis and Antimicrobial Activity of -tetranitrocalix[4]arene Derivative. Polycycl Aromat. 2016;36(4):554-63.

Nimsea SB, Kim T. Biological applications of functionalized calixarenes. Chem Soc Rev. 2013;42:366-86.

Perret F, Coleman AW. Biochemistry of anionic calix[n]arenes. J Chem Commun. 2011:47:7303-19.

Pinto AC, Abdala RV. Synthesis of chiral pyrrolidine and pyrrole derivatives through the chemoselective Dieckmann reaction of $\alpha, \beta$-aminodiesters. Tetrahedron-Asymmetr. 2000;11:4239-43.

Rao KG, Chakraborty D. Synthesis, characterization and antibacterial evaluation of some potent 2-substituted benzimidazole analogues. Int J Pharm Sci Drug Res. 2014;6:67-9.

Saba Muneer, Shahabuddin Memon, Qadeer Khan Panhwar, Faryal Khushik, Tahira Sarwar Khokhar, Agha Asad Noor. Synthesis and Antimicrobial Activity of -tetranitrocalix[4]arene Derivative. Polycyclic Aromatic Compounds. 2015; 36(4):554-563

Suzuki S, Sano F, Yuki H. Studies on antiviral agents. IV. Biological activity of tenuazonic acid derivatives. Chem Pharm Bull. 1967;15:1120-22.

Volonterio A, Zanda M. Multicomponent, one-pot sequential synthesis of 1,3,5and 1,3,5,5-substituted barbiturates. J Org Chem. 2008;73:7486-97.

Wang LZ, Li XQ, An YS. 1,5-Benzodiazepine derivatives as potential antimicrobial agents: design, synthesis, biological evaluation, and structure-activity relationships. Org Biomol Chem. 2015;13:5497-9.

Zgoda JR, Porte JR. A convenient microdilution method for screening natural products against bacteria and fungi. J Pharm Bio. 2001;39:221-25.

\section{Submit your manuscript to a SpringerOpen ${ }^{\mathcal{O}}$ journal and benefit from:}

- Convenient online submission

- Rigorous peer review

- Immediate publication on acceptance

- Open access: articles freely available online

- High visibility within the field

- Retaining the copyright to your article

Submit your next manuscript at springeropen.com 